\title{
Metallization of Hydrogen and Other Small Molecules at 100 GPa Pressures
}

\author{
W.J. Nellis
}

This article was submitted to European High Pressure Research Group Conference 39, Santander, Spain, September 16-19, 2001

\section{August 17, 2002}

U.S. Department of Energy

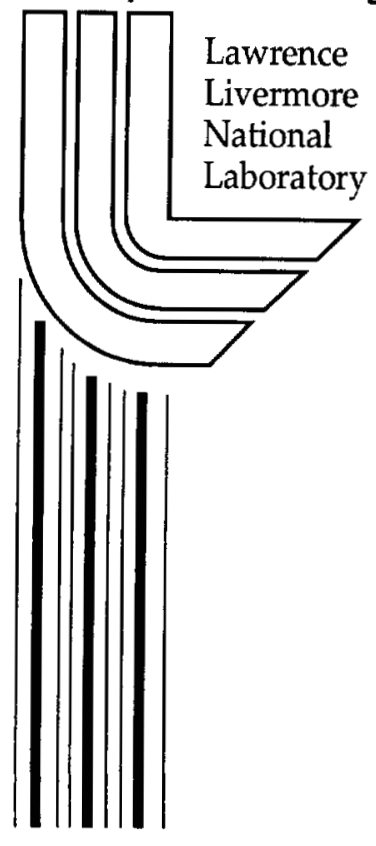

Approved for public release; further dissemination unlimited 


\section{DISCLAIMER}

This document was prepared as an account of work sponsored by an agency of the United States Government. Neither the United States Government nor the University of California nor any of their employees, makes any warranty, express or implied, or assumes any legal liability or responsibility for the accuracy, completeness, or usefulness of any information, apparatus, product, or process disclosed, or represents that its use would not infringe privately owned rights. Reference herein to any specific commercial product, process, or service by trade name, trademark, manufacturer, or otherwise, does not necessarily constitute or imply its endorsement, recommendation, or favoring by the United States Government or the University of California. The views and opinions of authors expressed herein do not necessarily state or reflect those of the United States Government or the University of California, and shall not be used for advertising or product endorsement purposes.

This is a preprint of a paper intended for publication in a journal or proceedings. Since changes may be made before publication, this preprint is made available with the understanding that it will not be cited or reproduced without the permission of the author.

This report has been reproduced directly from the best available copy.

Available electronically at http://www.doc.gov/bridge

Available for a processing fee to U.S. Department of Energy

And its contractors in paper from

U.S. Department of Energy

Office of Scientific and Technical Information

P.O. Box 62

Oak Ridge, TN 37831-0062

Telephone: (865) 576-8401

Facsimile: (865) 576-5728

E-mail: reports@adonis.osti.gov

Available for the sale to the public from

U.S. Department of Commerce

National Technical Information Service 5285 Port Royal Road

Springfield, VA 22161

Telephone: (800) 553-6847

Facsimile: (703) 605-6900

E-mail: orders@ntis.fedworld.gov

Online ordering: http://www.ntis.gov/ordering.htm

OR

Lawrence Livermore National Laboratory

Technical Information Department's Digital Library

http://www.llnl.gov/tid/Library.html 
Metallization of Hydrogen and Other Small Molecules at $100 \mathrm{GPa}$ Pressures

W. J. Nellis

University of California

Lawrence Livermore National Laboratory

Livermore, California 94550

Fluid hydrogen, oxygen, and nitrogen become metallic at $100 \mathrm{GPa}(1$ Mbar) pressures. Disorder is the primary reason for observing a metal at lower pressures in the fluid than expected for the ordered solid. This metallic transition is similar to those observed in fluid $\mathrm{Cs}$ and $\mathrm{Rb}$ by Hensel et al. All five undergo a Mott transition from a semiconducting to metallic fluid with the same electrical conductivities. In contrast, water is a proton conductor at pressures up to $200 \mathrm{GPa}$. Extreme conditions were achieved for $100 \mathrm{~ns}$ with a reverberating shock wave generated with a two-stage light-gas gun.

Email: nellis1@llnl.gov

Key words: hydrogen, metallization, shock pressure, fluid, Mott transition

\section{Introduction}

Hydrogen at high pressures has been a major scientific issue ever since it was predicted to undergo molecular dissociation to a monatomic metallic solid at a pressure $\mathrm{P}$ of $\sim 25 \mathrm{GPa}$ at temperature $\mathrm{T}=0 \mathrm{~K}$ [1]. Because Jupiter is composed of $\sim 90$ at. \% hydrogen, convective dynamo action of metallic fluid hydrogen at high pressures causes the magnetic field of Jupiter [2,3]. Hydrogen becomes metallic via a Mott transition at $140 \mathrm{GPa}$, ninefold compressed initial liquid density, and $2600 \mathrm{~K}$ achieved in the fluid with a reverberating shock wave [4-6]. Both oxygen [7] and nitrogen [8] undergo Mott transitions, as expected. In contrast, dense water is a fluid proton conductor up to $180 \mathrm{GPa}$, as expected, and predicted to metallize above $300 \mathrm{GPa}$ and $7000 \mathrm{~K}[9,10]$. 
Temperature is finite because shock compression is fast and adiabatic. Fig. 1 illustrates the effect of pressure rise time. Fig. 1a shows the cases in which pressure increases in one sharp shock and the case in which pressure increases in $\sim 10$ shocks to the same final pressure. Single-shock compression produces higher temperatures and modest density, while multiple shocks produce lower temperatures and higher densities close to the 0-K isotherm (Fig. 1b).

Predicted metallization at $\mathrm{T}=0 \mathrm{~K}$ ranges from 25 to $2000 \mathrm{GPa}$ [1,11]. Metal is not observed to $340 \mathrm{GPa}$ [12-14]. Theory puts metallization of the molecular crystal above $430 \mathrm{GPa}$ [15]. The Wigner transition is estimated at $\sim 620 \mathrm{GPa}$ [16]. If a cell is heated statically a few $100 \mathrm{~K}$, hydrogen diffuses out of the cell before a measurement can be made [17]. However, the $\sim 100 \mathrm{~ns}$ lifetime of a shock at a few $1000 \mathrm{~K}$ is long for thermal equilibrium and too short to lose hydrogen by mass diffusion and chemical reactions.

\section{Experiment}

Multiple shocks were achieved with a reverberating shock generated with a two-stage gun in a sample sufficiently large to measure dc conductivity [5]. Pressures are known to $1 \%$ from measurements. Densities and temperatures were calculated. Resistivities $\rho$ are plotted in Fig. 2 as $\log (\rho)$ versus shock pressure P. Similar results were obtained with explosives [18].

III. Mott Transition in Fluid Hydrogen

The change of slope at $140 \mathrm{GPa}$ in Fig. 2 is the nonmetal-metal transition. The regime $93-120 \mathrm{GPa}$ is thermally activated. The data fit gives a mobility gap of $E_{g}(D)=1.22-(62.6)(D-0.30)$, with $E_{g}(D)$ in ev and $D$ in mol 
$\mathrm{H}_{2} / \mathrm{cm}^{3}$. Conductivities from this exponential fit differ from measured values within the error bars.

The metallic state is achieved because pressure reduces the $15 \mathrm{ev}$ gap and thermal disorder fills it in until $\mathrm{E}_{\mathrm{g}} / \mathrm{k}_{\mathrm{B}}=\mathrm{T} \sim 2600 \mathrm{~K}$, where $\mathrm{E}_{\mathrm{g}}$ is smeared out thermally and the electronic system has a Fermi surface $\left(E_{g}=19 \mathrm{ev}\right)$. Since $\mathrm{T} / \mathrm{T}_{\mathrm{F}} \sim 0.01$, metallic hydrogen is highly degenerate. Fluid hydrogen becomes metallic via a continuous transition from semiconductor to metal. Considerations of macroscopic $E_{g}$ and $E_{d i s s}$, the dissociation energy, suggest that these conductivities are sensitive primarily to electronic excitation, with a small amount of dissociation. However, microscopic considerations below suggest that metallic hydrogen is essentially monomeric.

Tight-binding MD [19] shows that metallic hydrogen at $3000 \mathrm{~K}$ has a peak in the proton-proton pair distribution function at the separation distance between protons in the molecule and that "molecules" or dimers are short-lived $\left(\sim 10^{-14} \mathrm{~s}\right)$. Kinetic, vibrational, and rotational energies of the transient pairs are comparable. Conduction electrons have a very short mean free path, the distance between adjacent particles $(\sim 2 A)$. This is a strongscattering system characteristic of minimum metallic conductivity.

Fluid $\mathrm{Cs}, \mathrm{Rb}$, and $\mathrm{H}$ at $\sim 2000 \mathrm{~K}$ metallize with a conductivity of 2000 $(\Omega-\mathrm{cm})^{-1}$ at the same scaled density $D_{m}{ }^{1 / 3} a^{*}=0.38$, where $D_{m}$ is the density of atoms at metallization and $\mathrm{a}^{*}$ is the effective Bohr radius [20].

IV. Density at Metallization and Minimum Metallic Conductivity 
The Herzfeld criterion, which depends only on polarization of the atom [21], gives a metallization density of $0.60 \mathrm{~mol} \mathrm{H} / \mathrm{cm}^{3}$, within $7 \%$ of 0.64 $\mathrm{mol} \mathrm{H} / \mathrm{cm}^{3}$ determined in III. This agreement and short dimer lifetimes $\left(\sim 10^{-14} \mathrm{~s}\right)$ suggest that fluid metallic hydrogen is essentially monomeric.

Metallic conductivity, $2000(\Omega-\mathrm{cm})^{-1}$, is the minimum conductivity of a metal $\sigma_{\min }=2 \pi \mathrm{e}^{2} /(3 \mathrm{hd})$, where $\mathrm{h}$ is Planck's constant and $\mathrm{d}=\mathrm{D}_{\mathrm{m}}{ }^{-1 / 3}$. At metallization density, $0.60 \mathrm{~mol} \mathrm{H} / \mathrm{cm}^{3}, \sigma_{\min }=6000(\Omega-\mathrm{cm})^{-1}$, in good agreement with experiment. For $\mathrm{H}_{2}, \sigma_{\min }=5000(\Omega-\mathrm{cm})^{-1}$. Conductivity cannot resolve whether hydrogen is monatomic or diatomic. Metallic conductivities in good agreement with experiment were calculated with the Ziman model [22] and with tight-binding molecular dynamics [23]. The latter show that the nonmetal-metal transition in hydrogen is density-driven.

\section{ACKNOWLEDGMENTS}

This work was performed under the auspices of U.S. Department of Energy by the University of California Lawrence Livermore National Laboratory under Contract No. W-7405-ENG-48.

\section{References}

[1] Wigner, E. and Huntington, H. B. (1935). J. Chem. Phys., 3, 764.

[2] Stevenson, D. J. (1983). Rep. Prog. Phys., 46, 555.

[3] Nellis, W. J., Weir, S. T., and Mitchell, A. C. (1996). Science 273, 936. 
[4] Weir, S. T., Mitchell, A., and Nellis, W. (1996). Phys. Rev. Lett., 76, 1860.

[5] Nellis, W. J., Weir, S. T., and Mitchell, A. (1999). Phys. Rev. B, 59, 3434.

[6] Nellis, W. J. (2000). Sci. Am., May, 60.

[7] Bastea M., Mitchell A., and Nellis W. J. (2001). Phys. Rev. Lett., 86, 3108.

[8] Chau R. and Nellis, W. J., to be published.

[9] Chau, R., et al. (2001). J. Chem. Phys., 114, 1361.

[10] Cavazzoni, C., et al. (1999). Science, 283, 44.

[11] Alder, B . J. and Christian, R. H. (1960). Phys. Rev. Lett., 4, 450.

[12] Chen, H. N., Sterer E., and Silvera I. F. (1996). Phys. Rev. Lett., 76, 1663.

[13] Hemley, R. J. et al. (1996). Phys. Rev. Lett., 76, 1667.

[14] Narayana C., Luo H., Orloff J., and Ruoff, A. L. (1998). Nature, 393, 46.

[15] Ashcroft, N. W. and Johnson, K. A. (2000). Nature, 403, 632.

[16] Loubeyre, P., et al, (1996).Nature, 383, 702.

[17] Datchi, F., Loubeyre, P., and Letoullec, R. (2000). Phys. Rev. B, 61, 6535.

[18] Fortov, V. E., et al. (1999). JETP Lett., 69, 926.

[19] Lenosky, T. J., et al. (1997). Phys. Rev. B, 55, R11907.

[20] Hensel, F. and Edwards, P. (1996). Phys. World, 4, 43.

[21] Herzfeld, K. F. (1927). Phys. Rev., 29, 701.

[22] Nellis W. J., Louis A. A., and Ashcroft N. W. (1998). Philos. Trans. R. Soc. London, Ser. A, 356, 119.

[23] Kress, J., et al. In: Strongly Coupled Coulomb Systems, edited by G. J. Kalman, J. M. Rommel, and K. Blagoev (Plenum, New York,1998), pp. 331-335. 

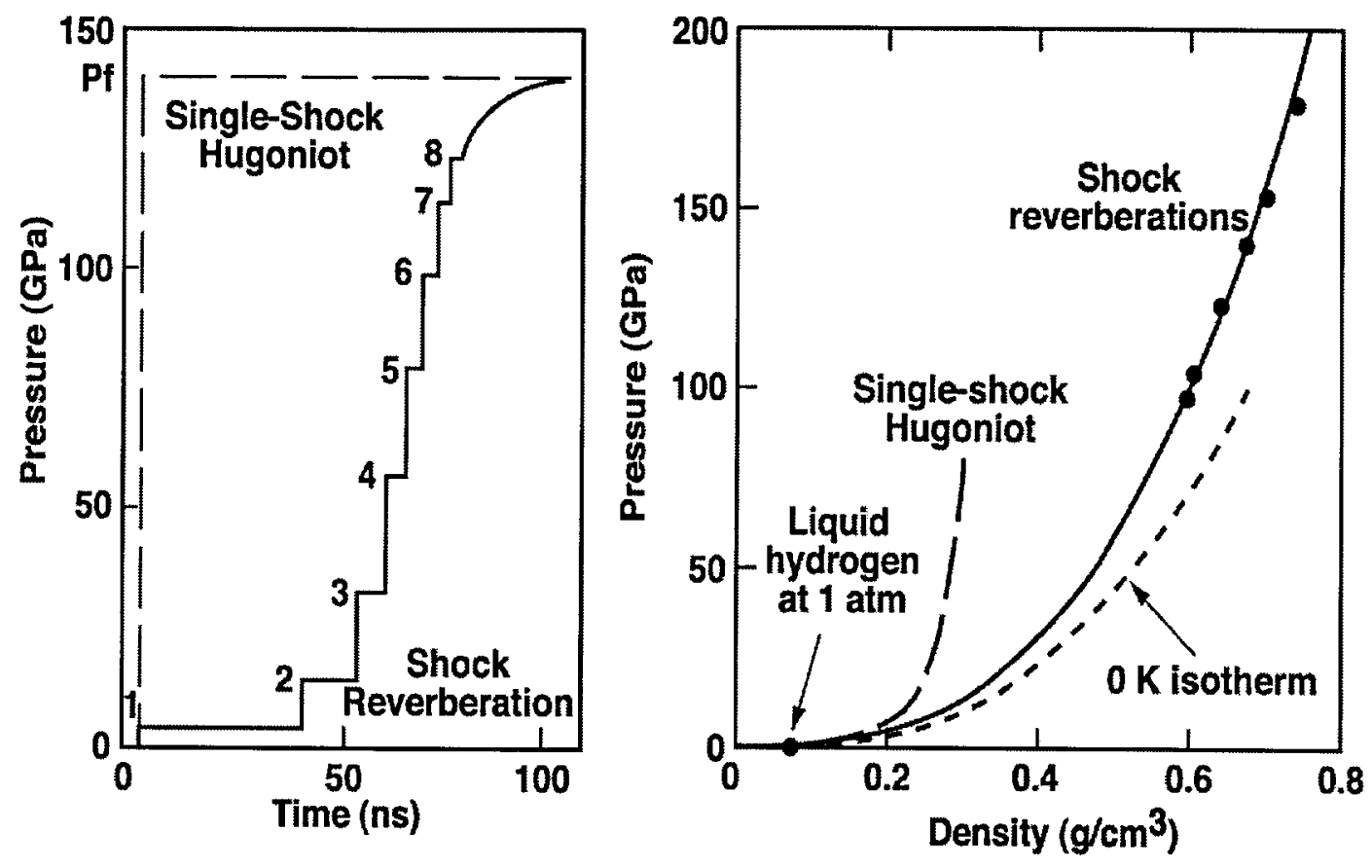

Fig. 1. Effect of time over which pressure is applied on thermodynamic states. One strong shock produces high thermal and total pressures (long-dashed cuve). Many shocks produce substantially lower thermal pressures and higher densities (solid curve) close to 0-K isotherm (short-dashed curve) [5].

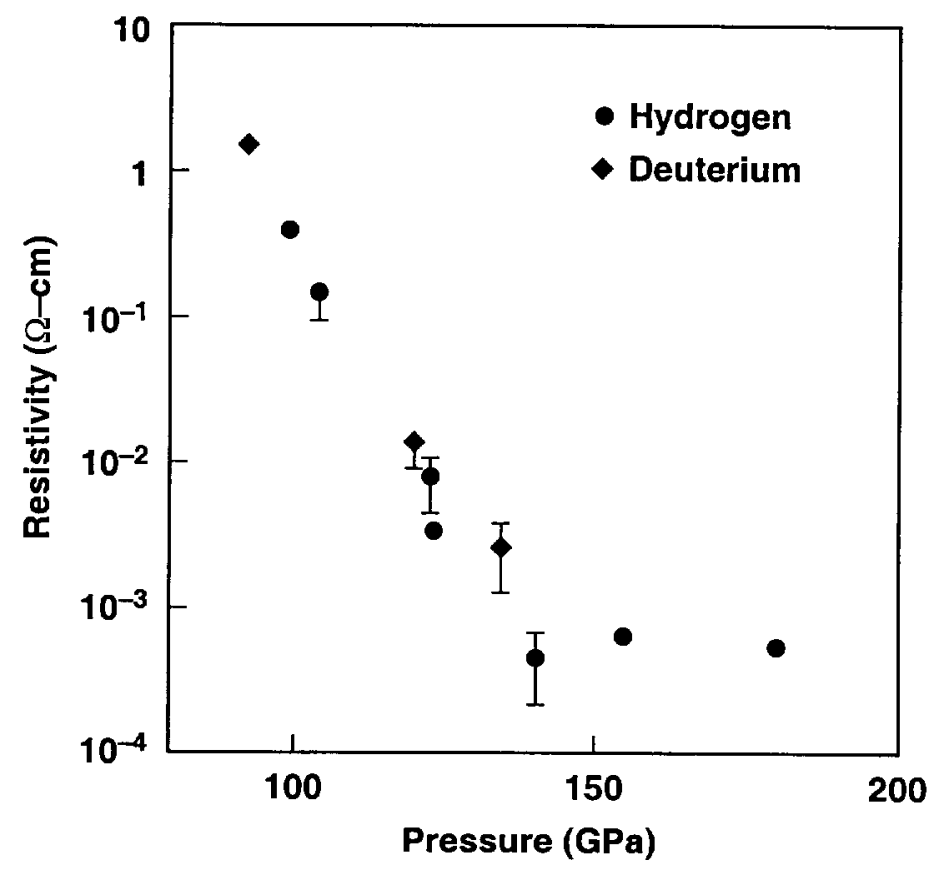

Fig. 2. Logarithm of measured electrical resistivities plotted versus shock reverberation pressure [5]. Similar results are reported in [20]. 